\title{
Erratum to: Resolving Disagreement Through Mutual Respect
}

\author{
Carlo Martini $\cdot$ Jan Sprenger $\cdot$ Mark Colyvan
}

Published online: 20 November 2013

(C) Springer Science+Business Media Dordrecht 2013

\section{Erratum to: Erkenn (2013) 78:881-898 DOI 10.1007/s10670-012-9381-8}

\section{Errata List}

Dietrich, F., \& Christian List. (2011). The aggregation of propositional attitudes: Towards a general theory. Oxford Studies in Epistemology, 3, 215-234.

(Cor) Dietrich, F., \& List C. (2010). The aggregation of propositional attitudes: Towards a general theory. In Oxford Studies in Epistemology, Volume 3, T. S. Gendler and J. Hawthorne (eds.): 215-234.

Keith, L. (1976). When rational disagreement is impossible. Noûs, 10, 327-332.

Keith, L. (1983). Rationality as weighted averaging. Synthese, 57, 283-295.

(Cor) Lehrer, K. (1976). When rational disagreement is impossible. Nô̂s, 10, 327-332.

(Cor) Lehrer, K. (1983). Rationality as weighted averaging. Synthese, 57, 283-295.

The online version of the original article can be found under doi:10.1007/s10670-012-9381-8.

C. Martini $(\bowtie)$

Philosophy and Economics Program, Institut für Philosophie, University of Bayreuth, 95440 Bayreuth, Germany

e-mail: carlo.martini@uni-bayreuth.de

\section{J. Sprenger}

Tilburg Center for Logic and Philosophy of Science, Tilburg University, Tilburg,

The Netherlands

e-mail: j.sprenger@uvt.nl

M. Colyvan

Sydney Centre for the Foundations of Science, University of Sydney, Sydney, NSW 2006, Australia e-mail: mark.colyvan@sydney.edu.au 
Regan, H., Mark, C., \& Lisa, M.-N. (2006). A formal model for consensus and negotiation in environmental management. Journal of Environmental Management, 80, 167-176.

(Cor) Regan, H., Colyvan M., \& Markovchick-Nicholls L. (2006). A formal model for consensus and negotiation in environmental management. Journal of Environmental Management, 80, 167-176.

Steele K., Helen R., Mark C., Burgman, M. A. (2007). Right decisions or happy decision-makers?. Social Epistemology: A Journal of Knowledge, Culture and Policy, 21, 349-368.

(Cor) Steele K., Regan, H., Colyvan, M., Burgman, M. A. (2007). Right decisions or happy decision-makers?. Social Epistemology: A Journal of Knowledge, Culture and Policy, 21, 349-368. 